\title{
Ictiofauna acompanhante associada a pesca do camarão- da-amazônia Macrobrachium amazonicum (Heller, 1862) (Decapoda, Palaeomonidae): subsídios para gestão ambiental e ordenamento da pesca
}

\author{
Luan Campos Imbiriba ${ }^{1^{*}}$ (D), Yana Karine da Silva Coelho ${ }^{1}$ (D), Elizabete de Matos Serrão ${ }^{2}$ (D), Diego \\ Maia Zacardi ${ }^{3}$ (D) \\ ${ }^{1}$ Curso de Engenharia de Pesca, Universidade Federal do Oeste do Pará, Laboratório de Ecologia do Ictioplâncton e \\ Pesca em Águas Interiores, Rua Vera Paz, s/n (Unidade Tapajós), Santarém, Pará, Brasil. \\ ${ }^{2}$ Curso de Engenharia de Pesca, Laboratório de Ecologia do Ictioplâncton e Pesca em Águas Interiores, Rua Vera Paz, \\ s/n (Unidade Tapajós), Santarém, Pará, Brasil. \\ ${ }^{3}$ Universidade Federal do Oeste do Pará, Laboratório de Ecologia do Ictioplâncton e Pesca em Águas Interiores, Rua \\ Vera Paz, s/n (Unidade Tapajós), Santarém, Pará, Brasil. \\ * Autor para correspondência: luancmps93@gmail.com
}

Recebido em 25 de maio de 2020.

Aceito em 08 de dezembro de 2020.

Publicado em 31 de dezembro de 2020.

Resumo - As comunidades tradicionais do Baixo Amazonas no Pará possuem diversas atividades pesqueiras que geram emprego e renda para os pescadores. Uma dessas é a pesca do camarãoda-amazônia Macrobrachium amazonicum praticada às margens do rio Amazonas, próximo à cidade de Santarém (PA). Este trabalho tem como objetivo registrar a ictiofauna acompanhante da pesca do camarão-da-amazônia, bem como sua relação com a biomassa total, riqueza, captura por unidade de esforço (CPUE) e a proporção de peixes e camarões. Os dados foram coletados por meio do acompanhamento mensal em três armadilhas semi-fixas na área de pesca no período de fevereiro/2018 a janeiro/2019. As informações foram anotadas e organizadas em um banco de dados para facilitar as análises. Foram capturados um total de 2.136 peixes, com ocorrência de 24 famílias e 69 espécies, sendo Colomesus asellus mais abundante e Hypoptopoma elongatum com ocorrência em todos os meses. O comprimento total foi baixo e variou entre 32 e $275 \mathrm{~mm}$, sugerindo a participação de muitas espécies de pequeno porte e/ou indivíduos juvenis, com pouco ou sem valor comercial. A proporção de peixe/camarão foi de 0,02/35,24 kg indicando que $97 \%$ da produção pesqueira do camarão é constituída da espécie alvo, contudo, os peixes jovens são descartados geralmente mortos, impactando negativamente seu ciclo. A diversidade e equitabilidade variaram ao longo dos meses, apontando um padrão de distribuição sazonal relacionado ao regime hidrológico da região.

Palavras-chave: Pesca Incidental; Fauna acompanhante; Armadilha semifixa "matapi”; Camarãoda-amazônia; Manejo pesqueiro. 


\title{
Ichthyofauna bycatch associated with Amazonian shrimp fishing Macrobrachium amazonicum (Heller, 1862) (Decapoda, Palaeomonidae): subsidies for environmental management and fishery planning
}

\begin{abstract}
The traditional communities of the Lower Amazon in Pará have several fishing activities that generate jobs and income for fishers. These activities include fishing for the Amazonian shrimp Macrobrachium amazonicum practiced on the riverside of the Amazon River, around the city of Santarém (PA). The main objective of this work is to register information the ichthyofauna accompanying the Amazonian shrimp fishery, as well as its relationship with the total biomass, richness, catch per unit effort (CPUE) and the ratio of fish to shrimp. Data were collected through the monthly monitoring in three semi-fixed traps in the fishing area from February/2018 to January/2019. The data were annotated and organized in a database to facilitate analysis. A total of 2,136 fish belonging to 24 families and 69 species were caught. The species Colomesus asellus was the most abundant, and Hypoptopoma elongatum occurring in all sampling months. The total length was low and varied between $32 \mathrm{~mm}$ to $275 \mathrm{~mm}$, indicating the participation of many small-size species and juvenile individuals, of minor or no commercial interest. The proportion of fish-shrimp was of 0.02:35.24 kg, which demonstrates that $97 \%$ of the shrimp's fishery production consists of the target species. However, young fish are usually discarded dead, negatively impacting their life cycle. The indexes of diversity and equitability varied along the months. This variation indicates a seasonal distribution pattern regarding the region's hydrological regime.
\end{abstract}

Keywords: Incidental fishing; bycatch; "Matapi" semi-fixed traps; Amazonian shrimp; Fishing management.

\section{Ictiofauna acompañante asociada con la pesca del camarón amazónico Macrobrachium amazonicum (Heller, 1862) (Decapoda, Palaeomonidae): subsidios para la gestión ambiental y la ordenación pesquera}

Resumen - Las comunidades tradicionales del Baixo Amazonas en Pará tienen diversas actividades pesqueras que generan empleos e ingresos para los pescadores. Una de ellas es la pesca del camarón amazónico Macrobrachium amazonicum practicada en la región marginal del río Amazonas, cerca de la ciudad de Santarém (PA). Este trabajo tiene como objetivo registrar la ictiofauna acompañante de la pesca del camarón amazónico, así como su relación con la biomasa total, la riqueza, la captura por unidad de esfuerzo (CPUE) y la proporción de peces y camarones. Los datos fueron recolectados mediante monitoreo mensual en tres trampas semifijas en la zona de pesca de febrero/2018 a enero/2019. Los datos fueron anotados y organizados en una base de datos para facilitar el análisis. Se capturaron un total de 2.136 peces pertenecientes a 24 familias y 69 especies. La especie Colomesus asellus fue la más abundante y la Hypoptopoma elongatum se presentó en todos los meses de muestreo. La longitud total fue baja y varió entre $32 \mathrm{~mm}$ y $275 \mathrm{~mm}$, lo que indica la participación de muchas especies de pequeño tamaño y/o individuos jóvenes, con interés comercial menor o nulo. La proporción de peces/camarón fue de 0,02/35,24kg, lo que demuestra que el $97 \%$ de la producción pesquera del camarón consiste en la especie objetivo. Sin embargo, los peces jóvenes generalmente se descartan muertos, lo que impacta negativamente su ciclo de vida. La diversidad y equidad variaron a lo largo de los meses. Esta variación indica un patrón de distribución estacional relacionado con el régimen hidrológico de la región.

Palabras clave: Pesca Incidental; Fauna acompañante; Trampa semifija "matapi"; Camarón amazónico; Manejo pesquero. 


\section{Introdução}

No estado do Pará, principalmente na mesorregião do Baixo Amazonas, a pesca artesanal está presente em várias comunidades ao longo de seu território possuindo uma contribuição significativa no âmbito socioeconômico para a população ribeirinha, pois desempenha um papel fundamental na geração de emprego e renda, além de proporcionar uma fonte de alimento e fortalecimento cultural (Vaz et al. 2017; Silva e Faria-Junior 2018; Serrão et al. 2019). Dentre as multiplicidades de pescarias de cunho artesanal ocorrentes na região, a pesca do camarão Macrobrachium amazonicum (Heller, 1862), conhecido popularmente como camarão-da-amazônia, se destaca como uma das atividades pesqueiras praticadas pelas comunidades (Costa et al. 2016; Zacardi 2020).

O camarão-da-amazônia é um recurso pesqueiro que possui considerável importância econômica, largamente explorado comercialmente e de grande aceitação na região. É uma das principais espécies consumidas por todas as classes sociais e está presente em vários pratos da culinária regional (Maciel e Valenti 2009; Sousa et al. 2014). A pesca de camarão na região de Santarém é realizada por uma armadilha semifixa com estrutura de ferro galvanizado e tela de náilon, possuindo duas aberturas laterais para facilitar a entrada do camarão, dispostas nas margens do rio Amazonas, nos canais e lagos de várzea próximo a cidade.

Essas armadilhas são denominadas popularmente de matapi e confeccionadas pelos próprios pescadores (Coelho et al. 2020). Provavelmente, devido a utilização da tela de náilon esse apetrecho deve possuir baixa seletividade, promovendo a captura de camarões imaturos comprometendo a renovação dos estoques naturais. Além disso, retém biomassa indesejada denominada fauna acompanhante, também conhecida por "bycatch", prática comum e citada em outras pescarias de camarões (Costa et al. 2016; Maia et al. 2016).

A assembleia de peixes associada a esta pescaria pode ser potencialmente impactada com influência direta sob os recursos alimentares e sobrevivência das espécies, prejudicando o ciclo natural da ictiofauna e aumentando os riscos de redução dos estoques pesqueiros locais (Tischer e Santos 2001; Falcão et al. 2008). Os organismos apreendidos incidentalmente junto com as capturasalvo, muitas das vezes não sobrevivem ao manejo e os que sobrevivem, podem ou não crescerem até a fase adulta, o que torna essa prática uma das principais problemáticas do setor (Davies et al. 2009). Assim, estudos quali-quantitativos da fauna acompanhante são de fundamental importância para se avaliar possíveis impactos dessa atividade no ecossistema marginal ao longo do trecho baixo do rio Amazonas.

Neste contexto, o estudo tem como objetivo registrar os grupos componentes da ictiofauna acompanhante com relação a biomassa total, riqueza, captura por unidade de esforço e proporção de peixes e camarão-da-amazônia (M. amazonicum) capturados em Santarém (PA), como forma de avaliar possíveis impactos que a pesca de camarões exerce sobre as principais espécies de peixes, fornecendo informações importantes em termos ecológicos. Dessa forma, auxiliar futuras ações que possam melhorar a qualidade ambiental e fortalecer a gestão e ordenamento da atividade pesqueira. 


\section{Material e métodos}

\section{Área de estudo}

A coleta de dados da fauna acompanhante foi realizada mensalmente, no período de fevereiro de 2018 a janeiro de 2019. Foram amostradas e acompanhadas as despescas "in loco" de três armadilhas semifixas (matapi), situadas na região marginal direita do rio Amazonas, $\left(2^{\circ} 26^{\prime} 09.8^{\prime \prime} \mathrm{S}\right.$ $54^{\circ} 40^{\prime} 54.1^{\prime \prime} \mathrm{W}, 2^{\circ} 27^{\prime} 09.0^{\prime \prime} \mathrm{S} 54^{\circ} 38^{\prime} 58.3^{\prime \prime} \mathrm{W}$ e $2^{\circ} 26^{\prime} 33.0^{\prime \prime} \mathrm{S} 54^{\circ} 40^{\prime} 33.4^{\prime \prime} \mathrm{W}$ ), em frente a área urbana da cidade de Santarém, a uma distância de 500 metros do lago Maicá e 1,5 km do Porto dos Milagres, onde fica localizado o principal ponto de comercialização dos camarões capturados (Figura 1).

Figura 1. Localização da área de pesca do camarão-da-amazônia (M. amazonicum) em Santarém, Baixo Amazonas, Pará, com destaque georreferenciado de cada armadilha nos pontos de despesca.

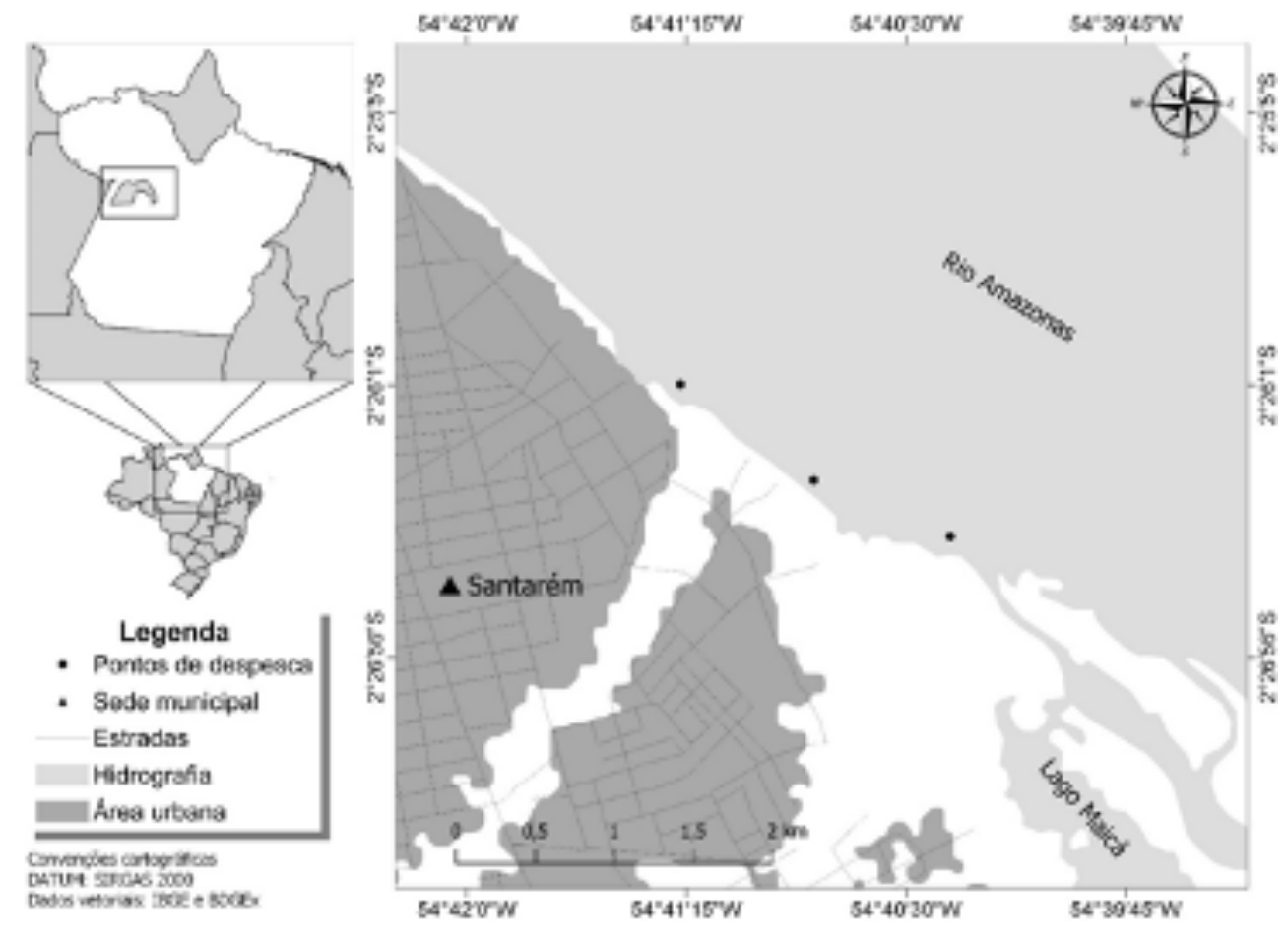

A pluviosidade média local é de $2.200 \mathrm{~mm} /$ ano, com período mais chuvoso registrado entre os meses de dezembro e junho, e o período mais seco entre os meses de julho a novembro, quando os índices pluviométricos diminuem consideravelmente (Silva et al. 2016).A área localiza-se em uma região que sofre bastante influência da foz Rio Tapajós e no regime hidrológico passando por quatro fases no ano enchente, cheia, vazante e seca (Bentes et al. 2018; Ponte et al. 2019).

A região possui 13 pescadores que atuam nessa atividade, com média de 3 matapis por pescador, no qual cada um confecciona seu próprio matapi. A despesca é feita sem utilização de gelo, posteriormente ela é realizado um cozimento para a comercialização. A comercialização do camarão é feita pelas mulheres no mercados da cidade, com rendimento mensal de 1 a 3 salários mínimos (Coelho et al. 2020).

Os pescadores denominam essa região na qual praticam a atividade pesqueira de "araçazeiro". Essa área sofre bastante influência do rio Tapajós principalmente durante o primeiro semestre do 
Ictiofauna acompanhante associada a pesca do camarão-da-amazônia Macrobrachium amazonicum (Heller, 1862) (Decapoda, Palaeomonidae): subsídios para gestão ambiental e ordenamento da pesca

ano, período de águas altas (janeiro a julho). A cidade de Santarém concentra um dos maiores pontos de desembarque e comercialização de pescado da Amazônia e o principal polo do Baixo Amazonas, devido as potencialidades naturais dos inúmeros ambientes de várzea existentes na região (Vaz et al. 2017; Zacardi 2020).

\section{Coleta de campo}

As armadilhas semifixas (matapis), já descritas por Coelho et al. (2020), utilizadas na pesca de camarão-da-amazônia foram supervisionadas por meio de embarcações da frota artesanal (canoas de madeira à remo ou à propulsão de motor rabeta) responsáveis pelo deslocamento até as áreas de captura e transporte da produção. Essas armadilhas não possuem um tamanho padrão, geralmente, ultrapassam o tamanho de 2,5 metros de altura por 2 metros de comprimento (Figura 2A e Figura 2B). Na parte da frente apresenta 2 aberturas de 4 centímetros de comprimento com altura passando de 1 metro (Figura 2C). Em sua lateral possui outra abertura para entrada do pescador fazer a despesca (Figura 2D), e na costa do matapi, possui um dispositivo adaptado com uma tela maior de permite a passagem de camarões menores e outros organismos pequenos para fora (Figura 2E).

Figura 2. (A) e (B) pescadores retirando matapi da água para despesca; (C) ilustração da parte frontal do matapi; (D) lateral do matapi com uma abertura central; (E) dispositivo na costa da armadilha para facilitar a saída de pequenos camarões e outros organismos.

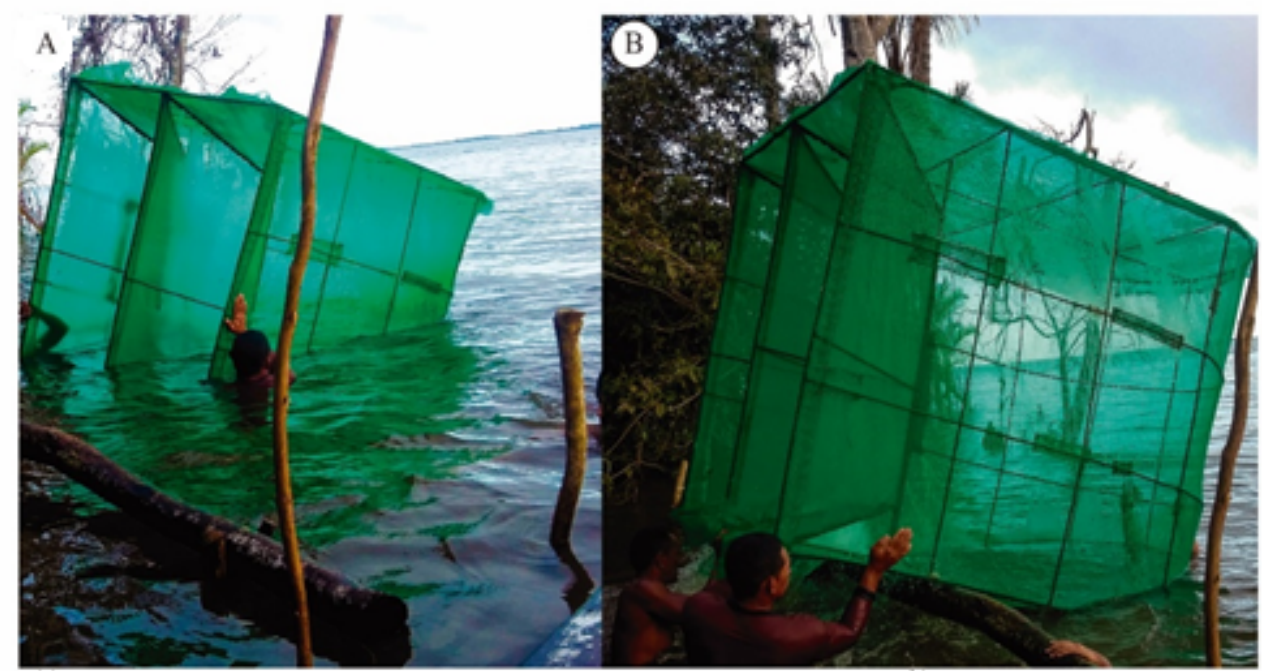

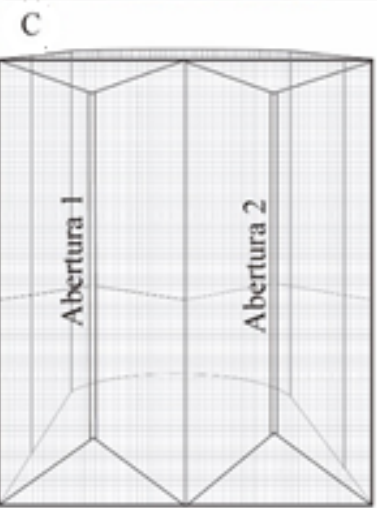

Frente
D

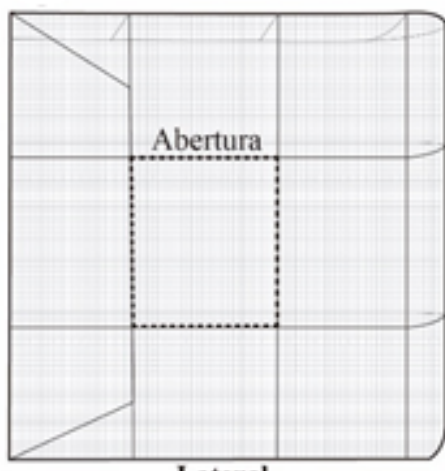

Lateral
E

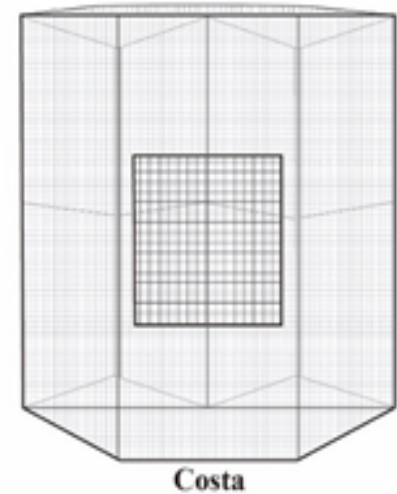


A pesca de camarão-da-amazônia ocorre no período noturno (18 às 6h), totalizando 12 horas de permanência da armadilha na água. Foram realizadas uma única coleta por mês, em três armadilhas fixas na área de pesca. Os peixes (ictiofauna acompanhante do camarão) presentes no interior de cada armadilha foram acondicionados em sacos plásticos devidamente etiquetados e armazenados em caixas térmicas com gelo para identificação em laboratório.

No laboratório, foi registrado o peso total ( $\mathrm{g}$ ) de cada espécie com balança digital com precisão de 0,01 g e medido o comprimento total $(\mathrm{CT})(\mathrm{mm})$ de cada exemplar com auxílio de paquímetro com precisão $0,01 \mathrm{~mm}$ e ictiômetro. Posteriormente, os espécimes eram separados por morfotipo para facilitar o processo de identificação taxonômica e registrar o número de espécies.

Os exemplares foram identificados até o menor nível taxonômico possível, utilizando-se chaves e livros regionais específicos (Ferreira et al. 1998; Galvis et al. 2006; Ferreira et al. 2007; Hercos et al. 2009; Queiroz et al. 2013; Ohara et al. 2017), e quando necessário alguns espécimes foram confirmados por especialistas, os indivíduos danificados e, por isso, impossíveis de identificação foram classificados como "Não identificados". Todo o material coletado está sendo preparado para ser incorporado e catalogado na Coleção Ictiológica da Universidade Federal do Oeste do Pará sob os cuidados do curador Frank Raynner Vasconcelos Ribeiro.

\section{Análise de dados}

As informações da ictiofauna acompanhante da pesca do camarão foram armazenadas em um banco de dados no software Access para facilitar a interpretação dos dados que foram agrupados por meses de coleta. Utilizou-se estatística descritiva para verificar a variação do tamanho dos exemplares (comprimento mínimo e máximo, amplitude de tamanho, média e desvio padrão de cada espécie).

Com o propósito de verificar diferenças temporais na estrutura da comunidade de peixes, foram efetuadas análises das frequências de ocorrência mensal da ictiofauna: OC: $n / N^{\star} 100$, onde $n=$ número de vezes que a espécie ocorreu e $\mathrm{N}$ = número total de meses coletados. A abundância total das espécies registradas no período de coleta foi classificada em três categorias seguindo os critérios de Ansari et al. (1995): regular (9 a 12 meses); sazonal (6 a 8 meses) e ocasional (1 a 5 meses).

A captura por unidade de esforço (CPUE) foi calculada mensalmente pela quantidade da biomassa $(\mathrm{kg})$ da ictiofauna acompanhante e da quantidade de camarão-da-amazônia e quantidade de indivíduos $(\mathrm{N})$ capturados pelo tempo em que as armadilhas permaneceram na água (h). Para a determinação da participação relativa da fauna íctica em relação a captura da espécie alvo foi utilizado a soma das capturas mensais de todos os indivíduos pertencentes a essa pescaria.

Para avaliar a composição da ictiofauna acompanhante foram calculados o índice de diversidade de Shannon-Wiener ( $\left.\mathrm{H}^{\prime}\right)$ e de equitabilidade de Pielou (J'), bem como a dominância das espécies durante o período estudado e criado o diagrama de Whittaker (Magurran 2004). Para verificar possíveis diferenças significativas na abundância de peixes ao longo dos meses de amostragens foi realizada uma ANOVA unifatorial e quando detectada diferença significativa $(\mathrm{p}<0,05)$ foi aplicado o teste a posteriori de Tukey, essas análises também foram utilizadas na CPUE (Kg/h e N/h). A análise de similaridade foi realizada utilizando o índice de Bray-Curtis através da abundância total de indivíduos e representado graficamente em um cluster. As análises foram realizadas no software R Studio 3.4.4 (R Core Team 2018), com auxílio do pacote vegan (Oksanen et al. 2016). 
Ictiofauna acompanhante associada a pesca do camarão-da-amazônia Macrobrachium amazonicum (Heller, 1862) (Decapoda, Palaeomonidae): subsídios para gestão ambiental e ordenamento da pesca

\section{Resultados e Discussão}

Durante o período de estudo foram capturados 17,11 kg de peixes equivalente a 2136 indivíduos compondo a ictiofauna acompanhante da pesca do camarão-da-amazônia, classificados em sete ordens, 24 famílias, 50 gêneros e 69 espécies (Tabela 1). A maioria (55) das espécies foram classificadas como ocasionais $(79,71 \%)$, seguido de 8 espécies sazonais $(11,59 \%)$ e somente 6 espécies regulares $(8,70 \%)$ destacando a espécie Hypoptopoma elongatum Aquino \& Schaefer, 2010 que foi a única com ocorrência registrada em todos os meses de amostragem e Colomesus asellus a mais abundante.

Tabela 1. Composição específica da ictiofauna acompanhante associada a pesca do camarão-da-amazônia na cidade de Santarém (PA). Relação da abundância total $(\mathrm{N})$ e relativa (N\%) das espécies. Ocorrência mensal (OM), frequência de ocorrência (FO), classificação de ocorrência (CFO) do período estudado, $\mathrm{R}$ (Regular), S (Sazonal) e OC (Ocasional).

\begin{tabular}{llllll}
\hline Táxon & $\mathrm{N}$ & $\mathrm{N}(\%)$ & $\mathrm{OM}$ & $\mathrm{CFO}$ \\
\hline
\end{tabular}

\section{BELONIFORMES}

\section{Belonidae}

Potamorrhaphis eigenmanni MirandaRibeiro, 1915

\section{CHARACIFORMES}

\section{Acestrorhynchidae}

Acestrorhynchus falcirostris (Cuvier, 1819)

$\begin{array}{cccc}3 & 0,14 & 2 & \text { OC } \\ 3 & 0,14 & 2 & \text { OC } \\ 37 & 1,73 & 8 & \text { S }\end{array}$

Acestrorhynchus falcatus (Bloch, 1794)

\section{Anostomidae}

Abramites hypselonotus (Günther, 1868)

$\begin{array}{llll}1 & 0,05 & 1 & \mathrm{OC}\end{array}$

Leporinus fasciatus (Bloch, 1794)

$2 \quad 0,09 \quad 2 \quad$ OC

Leporinus friderici (Bloch, 1794)

$30,14 \quad 3 \quad$ OC

Pseudanos trimaculatus (Kner, 1858)

$51 \quad 2,39$

1

OC

\section{Characidae}

Hemigrammus sp.

Moenkhausia lepidura (Kner, 1858)

Roeboides affinis (Günther, 1868)

Roeboides myersii Gill, 1870

Tetragonopterus argenteus Cuvier, 1816

Tetragonopterus chalceus Spix \& Agassiz, 1829

$\begin{array}{llll}2 & 0,09 & 1 & \text { OC }\end{array}$

Chilodontidae

Chilodus punctatus Müller \& Troschel, 1844

2

$\begin{array}{llll}4 & 0,19 & 1 & \text { OC }\end{array}$

$95 \quad 4,45 \quad 8 \quad 5$

$32 \quad 1,50 \quad 2 \quad$ OC

$\begin{array}{llll}6 & 0,28 & 3 & \text { OC }\end{array}$

$17 \quad 0,80 \quad 2 \quad$ OC




\section{Curimatidae}

Curimatella sp.

Psectrogaster rutiloides (Kner, 1858)

\section{Táxon}

\section{$\mathbf{N}$}

$\mathbf{N}(\%)$

OM

CFO

Cynodontidae

Hydrolycus scomberoides (Cuvier, 1819)

$\begin{array}{llll}3 & 0,14 & 2 & \text { OC } \\ 1 & 0,05 & 1 & \text { OC } \\ 2 & 0,09 & 1 & \text { OC }\end{array}$

\section{Gasteropelecidae}

Thoracocharax sp.

\section{Hemiodontidae}

Hemiodus argenteus Pellegrin, 1909

Hemiodus sp.

Hemiodus unimaculatus (Bloch, 1794)

\section{Iguanodectidae}

Bryconops sp.$$
1
$$

$$
0,0
$$

$\begin{array}{cccc}7 & 0,33 & 2 & \text { OC } \\ 8 & 0,37 & 3 & \text { OC } \\ 16 & 0,75 & 2 & \text { OC }\end{array}$

Serrasalmidae

Mylossoma aureum (Spix \& Agassiz, 1829)

$40,19 \quad 3 \quad$ OC

Pristobrycon calmoni (Steindachner, 1908)

10

Serrasalmus medinai Ramírez, 1965

5

Serrasalmus sp.

Serrasalmus spilopleura Kner, 1858

$$
5
$$

Triportheidae

Triportheus angulatus (Spix \& Agassiz, 1829)

82

Triportheus auritus (Valenciennes, 1850)

\section{CLUPEIFORMES}

\section{Engraulidae}

Lycengraulis batesii (Günther, 1868)

1

$$
0,05
$$

1

$\mathrm{OC}$

Pristigasteridae

Pellona flavipinnis (Valenciennes, 1837)

Pristigaster cayana Cuvier, 1829

$\begin{array}{llll}5 & 0,23 & 4 & \text { OC } \\ 1 & 0,05 & 1 & \text { OC }\end{array}$

\section{GYMNOTIFORMES}

\section{Sternopygidae}

Eigenmannia limbata (Schreiner, Miranda \& Ribeiro, 1903) 71

Sternopygus macrurus (Bloch \& Schneider, 1801)

$3,32 \quad 10$

$\mathrm{R}$ 


\begin{tabular}{llllll}
\hline & Táxon & $\mathrm{N}$ & $\mathrm{N}(\%)$ & $\mathrm{OM}$ & $\mathrm{CFO}$ \\
\hline PERCIFORMES & & &
\end{tabular}

\section{Cichlidae}

Caquetaia spectabilis (Steindachner, 1875)

Chaetobranchus flavescens Heckel, 1840

Crenicichla johanna Heckel, 1840

Crenicichla lugubris Heckel, 1840

Crenicichla reticulata (Heckel, 1840)

Crenicichla semicincta Steindachner, 1892

Crenicichla strigata Günther, 1862

Geophagus megasema Heckel, 1840

Mesonauta festivus (Heckel, 1840)

Mesonauta insignis (Heckel, 1840)

Pterophyllum scalare (Schultze, 1823)

$\begin{array}{cccc}3 & 0,14 & 2 & \text { OC } \\ 1 & 0,05 & 1 & \text { OC } \\ 5 & 0,23 & 3 & \text { OC } \\ 9 & 0,42 & 2 & \text { OC } \\ 40 & 1,87 & 10 & \text { R } \\ 8 & 0,37 & 2 & \text { OC } \\ 12 & 0,56 & 2 & \text { OC } \\ 26 & 1,22 & 8 & \text { S } \\ 5 & 0,23 & 2 & \text { OC } \\ 4 & 0,19 & 3 & \text { OC } \\ 2 & 0,09 & 1 & \text { OC }\end{array}$

\section{Sciaenidae}

Plagioscion squamosissimus (Heckel, 1840)

$10,05 \quad 1 \quad$ OC

\section{SILURIFORMES}

\section{Aspredinidae}

Pseudobunocephalus amazonicus (Mees, 1989)

$10,05 \quad 1 \quad$ OC

\section{Auchenipteridae}

Ageneiosus sp.

Ageneiosus ucayalensis Castelnau, 1855

$\begin{array}{llll}1 & 0,05 & 1 & \text { OC }\end{array}$

Auchenipterichthys longimanus (Günther, 1864)

$10,05 \quad 1 \quad$ OC

Auchenipterichthys sp.

$45 \quad 2,11 \quad 3 \quad$ OC

Centromochlus heckelii (DeFilippi, 1853)

$26 \quad 1,22$

$184 \quad 8,61$

5

$\mathrm{OC}$

\section{Doradidae}

Agamyxis pectinifrons (Cope, 1870)

Ossancora punctata (Kner, 1855)

Platydoras costatus (Linnaeus, 1758)

\section{Heptapteridae}

Pimelodella cristata (Müller \& Troschel, 1849)

$\begin{array}{cccc}3 & 0,14 & 3 & \text { OC } \\ 249 & 11,66 & 9 & \mathrm{R} \\ 4 & 0,19 & 2 & \text { OC } \\ & & & \\ 143 & 6,69 & 10 & \mathrm{R}\end{array}$




\begin{tabular}{lcccc}
\hline \multicolumn{1}{c}{ Táxon } & N & N(\%) & OM & CFO \\
\hline Loricariidae & 3 & 0,14 & 3 & OC \\
Aphanotorulus unicolor (Steindachner, 1908) & 3 & 0,14 & 1 & OC \\
Dekeyseria amazonica RappPy-Daniel, 1985 & 3 & 0,14 & 2 & OC \\
Farlowella amazonum (Günther, 1864) & 4 & 0,19 & 2 & OC \\
Farlowella oxyrryncha (Kner, 1853) & 5 & 0,23 & 3 & OC \\
Farlowella sp. & 164 & 7,68 & 12 & $\mathrm{R}$ \\
Hypoptopoma elongatum Aquino \& Schaefer, 2010 & 9 & 0,42 & 5 & OC \\
Hypostomus sp. & 13 & 0,61 & 4 & OC \\
Loricaria sp. & 12 & 0,56 & 4 & OC \\
Peckoltia sp. & & & & \\
Pimelodidae & 183 & 8,57 & 10 & $\mathrm{R}$ \\
Pimelodus blochii Valenciennes, 1840 & 3 & 0,14 & 3 & OC \\
Sorubim lima (Bloch \& Schneider, 1801) & & & & \\
TETRAODONTIFORMES & & & & \\
Tetraodontidae & 253 & & & \\
Colomesus asellus (Müller \& Troschel, 1849) & 395 & 18,49 & 11 & R \\
\hline Não identificados & & & \\
\hline Total & & & \\
\hline
\end{tabular}

A diversidade constatada na composição das capturas, a dominância de Ostariophysi e a maior frequência das ordens Characiformes e Siluriformes registradas nas amostras, é o padrão comum em rios neotropicais e não diferem de outros trabalhos desenvolvidos na região amazônica, em que esses grupos possuem grande influência na estrutura da fauna íctica (Corrêa et al. 2012; Franco et al. 2015; Loebens e Yamamoto 2016). Apesar de alguns indivíduos não apresentarem valor econômico e serem compostos por exemplares de pequeno porte, inúmeras espécies amostradas constituem fonte de alimento para os ribeirinhos, enquanto outras servem de forrageio básico para muitos peixes e aves, tornando importantes recursos para a cadeia trófica local.

Ressalta-se, ainda, que o número de espécies de peixes registrados no presente estudo (69), pode ser considerado elevado, principalmente quando se compara com o número da ictiofauna acompanhante (51) apontado pela pesca industrial dos camarões marinhos na costa norte do Brasil (Maia et al. 2016). Vale lembrar que não existe na legislação brasileira, medidas que contemplem o impacto ambiental causado sobre a fauna acompanhante (Sedrez et al. 2013).

Portanto, nota-se uma importante biodiversidade ictiofaunística nessa zona de pesca, e em virtude disso, a atividade pode favorecer o comprometimento da biota local, interferir no equilíbrio ecológico da comunidade ícticas, gerar impacto ambiental, desperdício de alimento e afetar a renda dos pescadores artesanais. 
A maioria dos exemplares capturados apresentaram comprimento total (CT) baixo, em destaque A. falcatus com tamanho mínimo de captura de 32,0 $\mathrm{mm}$ (CT M $\pm \mathrm{DP}=74,35 \pm 46,20$ $\mathrm{mm})$, O. punctata com 33,0 $\mathrm{mm}$ (CT M $\pm \mathrm{DP}=76,7 \pm 11,53 \mathrm{~mm})$, M. festivus com $36 \mathrm{~mm}$ (CT M \pm $\mathrm{DP}=46,34 \pm 12,34 \mathrm{~mm})$ e $A$. longimanus com $40 \mathrm{~mm}$ e $(\mathrm{CT} \mathrm{M} \pm \mathrm{DP}=89,27 \pm 11,06 \mathrm{~mm})$, as que obtiveram maiores tamanhos de captura foram $S$. macrurus com 275,0 $\mathrm{mm}$ (CT M $\pm \mathrm{DP}=215,23 \pm$ $35,59 \mathrm{~mm})$, E. limbata com 256,0 $\mathrm{mm}(\mathrm{CT} \mathrm{M} \pm \mathrm{DP}=160,50 \pm 47,99 \mathrm{~mm})$ e P. flavipinnis com 255,0 $\mathrm{mm}(\mathrm{CT} \mathrm{M} \pm \mathrm{DP}=186,5 \pm 46,54)$ (Tabela 2), indicando um grande número de espécies de pequeno porte e/ou indivíduos juvenis colonizando as margens do rio Amazonas.

Tabela 2. Variação da média e desvio padrão do comprimento padrão da ictiofauna acompanhante associada a pesca do camarão-da-amazônia, na cidade de Santarém (PA) $(\mathrm{CT}$ = Comprimento Total em $\mathrm{mm} ; \mathrm{M}=$ Média e DP = Desvio Padrão).

\begin{tabular}{|c|c|c|c|}
\hline Táxon & CT $(\mathrm{mm}) \mathrm{M}$ e DP & Táxon & CT $(\mathrm{mm}) \mathrm{M}$ e DP \\
\hline A. hypselonotus & 89,0 & Loricaria sp. & $121,67 \pm 31,27$ \\
\hline A. falcatus & $74,35 \pm 46,20$ & L. batesii & 118,0 \\
\hline A. falcirostris & $184 \pm 27,87$ & M. festivus & $46,34 \pm 12,34$ \\
\hline A. microlepis & $137,5 \pm 60,10$ & M. insignis & $66,75 \pm 12,28$ \\
\hline A. pectinifrons & $77 \pm 2,83$ & M. lepidura & $58,75 \pm 5,31$ \\
\hline Ageneiosus sp. & 114,0 & M. aureum & $83,5 \pm 3,11$ \\
\hline A. ucayalensis & 165,0 & O. punctata & $76,7 \pm 11,53$ \\
\hline A. unicolor & $97 \pm 16,97$ & Peckoltia sp. & 110,0 \\
\hline A. longimanus & $89,27 \pm 11,06$ & P. flavipinnis & $186,5 \pm 46,54$ \\
\hline Auchenipterichthys sp. & $89,49 \pm 13,49$ & P. cristata & $105,50 \pm 25,11$ \\
\hline Bryconops sp. & $72,34 \pm 3,52$ & P. blochii & $84,68 \pm 19,42$ \\
\hline C. spectabilis & $104,34 \pm 30,23$ & P. squamosissimus & 62,0 \\
\hline C. heckelii & $78,38 \pm 10,98$ & P. costatus & $88,25 \pm 2,87$ \\
\hline C. flavescens & 61,0 & P. eigenmanni & $187,85 \pm 22,25$ \\
\hline C. punctatus & $71,5 \pm 4,94$ & P. cayana & 109,0 \\
\hline C. asellus & $63,75 \pm 12,42$ & P. calmoni & $119,2 \pm 30,19$ \\
\hline C. johanna & $130,25 \pm 43,08$ & P. rutiloides & 130,0 \\
\hline C. lugubris & 97,0 & P. trimaculatus & $108,58 \pm 13,53$ \\
\hline C. reticulata & $105,32 \pm 15,81$ & P. amazonicus & 70,0 \\
\hline C. semicincta & $117,25 \pm 33,43$ & P. scalare & $78,5 \pm 10,60$ \\
\hline C. strigata & $176,67 \pm 58,38$ & R. affinis & $80,4 \pm 7,94$ \\
\hline Curimatella sp. & 95,0 & R. myersii & $86,88 \pm 29,14$ \\
\hline D. amazonica & $147 \pm 31,09$ & S. medinai & $99,2 \pm 7,12$ \\
\hline E. limbata & $160,50 \pm 47,99$ & Serrasalmus sp. & $73,13 \pm 4,67$ \\
\hline
\end{tabular}




\begin{tabular}{lc|lc} 
F. amazonum & $114 \pm 29,69$ & S. spilopleura & $70 \pm 12,38$ \\
F. oxyrryncha & $179,5 \pm 16,17$ & S. lima & $168 \pm 55,56$ \\
Farlowella sp. & $151 \pm 55,15$ & S. macrurus & $215,23 \pm 35,59$ \\
G. megasema & $103,73 \pm 16,17$ & T. argenteus & $90,5 \pm 34,20$ \\
Hemigrammus sp. & $52 \pm 4,24$ & T. chalceus & $66,88 \pm 9,23$ \\
H. argenteus & $87,28 \pm 11,94$ & Thoracocharax sp. & 56,0 \\
Hemiodus sp. & $78,12 \pm 5,54$ & T. angulatus & $102,68 \pm 22,17$ \\
H. unimaculatus & $85,32 \pm 8,13$ & T. auritus & $95,34 \pm 25,02$ \\
H. scomberoides & $217 \pm 15,55$ & & \\
H. elongatum & $81,12 \pm 17,83$ & & \\
Hypostomus sp. & $82,56 \pm 20,73$ & \\
L. fasciatus & $53 \pm 9,89$ & \\
L. friderici & $99,67 \pm 18,58$ & & \\
\hline Comprimento total $(\mathbf{C T}) \mathbf{m m}$ & & \\
\hline Mínimo & & \\
Máximo & & \\
Média & & \\
Amplitude & & \\
\hline
\end{tabular}

Pela variação da amplitude de comprimento total é possível notar que o intervalo pode abranger todo o ciclo de vida de algumas espécies de peixes, desde a fase juvenil até indivíduos sexualmente maduros, portanto, a área de pesca pode ser utilizada tanto para reprodução quanto para crescimento. De modo geral, o período de pesca do camarão coincide com o período de desenvolvimento inicial da maioria das espécies de peixes Amazônicos, tornando muito frequente a captura destes indivíduos em fase juvenil nas armadilhas. Essa dominância pode estar associada, ainda, a elevada dependência da mata ciliar para obtenção de alimentos e das áreas mais rasas como locais de proteção e abrigo (Brejão et al. 2013; Montag et al. 2018), maximizando o desenvolvimento e a sobrevivência da ictiofauna, sendo possível constatar que várias espécies de peixes e o camarãoda-amazônia habitam os mesmos ambientes (zona marginal) em algum momento do ciclo de vida.

A grande quantidade de exemplares com baixo comprimento total (adultos de pequeno porte) e elevada frequência de peixes jovens capturados se assemelham a outros tipos de pescarias de camarões (Santos et al. 2008; Fonseca e Souza 2013; Carvalho et al. 2019). A baixa incidência de peixes maiores neste estudo, não reflete necessariamente a ausência destes na área de estudo, uma vez que a armadilha é projetada primariamente para a pesca de camarões.

Contudo, a maior abundância e incidência de juvenis registrados nessa área de pesca, aliado a falta de legislação e ordenamento da pesca de camarão-da-amazônia pode apresentar a curto e/ou médio prazo algum grau de ameaça ou impacto, o que pode possibilitar decréscimo no potencial dos estoques da ictiofauna local e, consequentemente, no rendimento das pescarias, sendo possível 
presumir o efeito negativo que o aumento do número de armadilhas, em uma determinada área de pesca, pode exercer sobre os juvenis de diversas espécies. De acordo com Davies et al. (2009) e Souza et al. (2019) essa ictiofauna associada as pescarias de camarões se caracteriza em um dos principais problemas do manejo pesqueiro contemporâneo.

Foram capturados um total 636,02 kg de camarões e 17,35 kg de peixes, com rendimento médio por matapi de 17,67/0,48, respectivamente. A participação relativa da biomassa de camarão em relação a ictiofauna acompanhante foi de $97,39 \%$ para $2,61 \%$, respectivamente, com uma proporção de peixe/camarão de 0,02/35,24 kg. A captura por unidade de esforço (CPUE) do período amostral não apresentou diferenças significativas $(\mathrm{p}>0,05)$. A média da biomassa $(\mathrm{CPUE} / \mathrm{kg} / \mathrm{h})$ foi de $4,33 \pm 0,91$ para camarão e $0,12 \pm 0,02$ para ictiofauna, com os maiores valores registrados nos meses de junho e novembro (Figura 3A). Também não foi constatado diferença significativa $(\mathrm{p}>0,05)$ em relação aos números de exemplares (CPUE/N/h), com os maiores valores médios constatados em junho $(20,75 \pm 3,01)$ e outubro $(17,58 \pm 2,78)$ (Figura 3B).

Figura 3. Variação mensal da captura por unidade de esforço (CPUE) da biomassa de camarão-daamazônia e ictiofauna acompanhante (a) e abundância (b), intervalos de confiança $(\alpha=0,05)$ em linhas verticais.

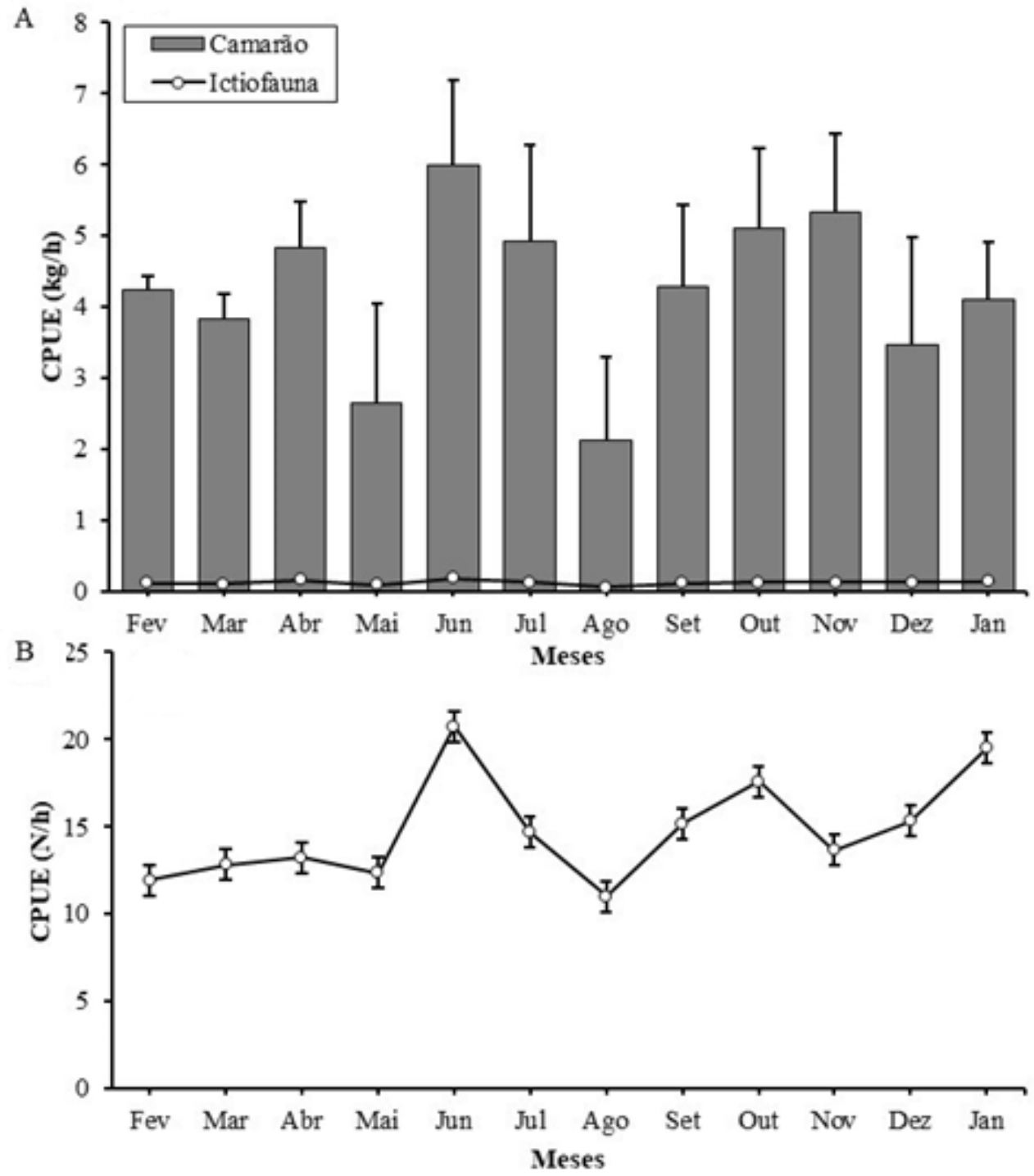


A biomassa de camarões-da-amazônia capturada em Santarém foi consideravelmente superior à ictiofauna acompanhante, diferentemente de outros tipos de pescaria de camarões, como aquelas praticadas com redes de arrastos, onde o volume da fauna acompanhante é extremamente superior (mais de 87\%), com elevados valores de descartes que podem atingir grandes proporções quando se determina a razão entre a biomassa da espécie alvo e a ictiofauna (peixes) capturada (Lima e Montagner 2014; Vieira et al. 2017; Pinheiro e Martins 2018; Farias et al. 2019). Nesse caso, a alta captura de fauna acompanhante reflete em baixa produtividade de camarões quando utilizado redes de arrastos, principalmente quando se comparada as armadilhas semifixas.

Os peixes capturados ainda são pouco aproveitados, geralmente são rejeitados ou descartados mortos, além de possuírem pouco ou nenhum valor de mercado por se tratar de indivíduos pequenos (Freitas et al. 2011; Souza et al. 2019). Essa situação demonstra uma possível eficiência na captura da espécie-alvo que aparentemente apresenta-se auto-regulada por variações ambientais (ciclo hidrológico local) e pela prática de pesca moderada, o que indica que a pesca com armadilhas (matapis) na área de estudo é praticamente monoespecífica, pois cerca de $97 \%$ da produção pesqueira é constituída da espécie alvo, resultados similares também foram descritos por Mérona et al. (2010) com pesca de camarões-da-amazônia e por isso são descartados geralmente mortos.

Não há um manejo comunitário que permita uma proteção para a ictiofauna acompanhante, visto que, são medidas importantes para a manutenção da espécie, realidade diferente encontrada em Gurupá - Pará, no qual o acordo de pesca do camarão trouxe importantes melhorias para o uso do recurso sem esgotar os recursos (Sousa et al. 2011). A captura da fauna acompanhante é o principal conflito territorial entre os pescadores de camarão e com os que pescam peixe na região, a justificativa principal é a quantidade de peixes pequenos capturados, com resultado disso, ocorre a destruição dos matapis ou furto de camarões (Coelho et al. 2020).

Deste modo, acredita-se que apesar da pressão, as espécies rejeitadas têm conseguido manter relativamente estável a diversidade biológica e populacional na região. Porém, é necessário um programa de acompanhamento e monitoramento constante dos desembarques e do esforço de pesca envolvido, para um melhor diagnóstico da atividade pesqueira no local.

Segundo Branco et al. (2005) a variabilidade temporal na abundância da fauna acompanhante, geralmente acompanham as flutuações da CPUE, dessa forma, essas variações podem significar mudanças sazonais na abundância dos peixes. $\mathrm{Na}$ área de pesca estudada, as maiores abundâncias e CPUE foram registrados durante os dois extremos do nível da água, na cheia (junho) e final de vazante e seca (outubro/novembro). Fato associado entre outros fatores: a retração e ampliação das águas sobre a região marginal do rio Amazonas.

No período de águas baixas o ambiente possibilita uma maior concentração dos peixes, já durante o período de águas altas há uma expansão dos habitats sob as áreas alagadas e, consequentemente, aumentam a disponibilidade de alimentos aos peixes. Portanto, as variações sazonais na abundância e CPUE, podem estar relacionadas aos ciclos reprodutivos dos peixes, as relações tróficas, disponibilidade de alimentos, áreas de pesca, época do ano e hidrodinâmica local com consequentes modificações quali-quantitativas em seus componentes ambientais e biológicos.

A composição da abundância e riqueza temporal da ictiofauna capturada no período de amostragem variou significativamente nos meses de junho e agosto (Teste de Tukey, $\mathrm{p}=0,027$ ). Destacam-se os meses de junho com um total de 249 peixes divididos em 28 espécies, seguido do mês de março (154) e 26 espécies, nos meses de abril (159) e maio (148) com 23 espécies cada. 
Agosto (132) e setembro (182), foram os meses que ocorreram o menor número espécies 10 e 14 , respectivamente (Figura $4 \mathrm{~A}$ e $4 \mathrm{~B}$ ).

Os índices de diversidade obtiveram oscilações ao longo do período de estudo, apresentando média de 2,24, o mês de junho apresentou maior diversidade (2,53). As menores diversidade foram registradas nos meses de agosto $(1,73)$, seguido do mês de julho e setembro (Figura $4 \mathrm{C}$ ). A equitabilidade de Pielou (J') calculada apresentou variações mensais, com média de 0,76, e o mês de novembro com o maior índice, já a menor foi observada nos meses de setembro, março e julho (Figura 4D).

Figura 4. Variação mensal da abundância (a), riqueza (b), índices de diversidade Shannon ( $\left.H^{\prime}\right)$ (c), equitabilidade de Pielou (J') (d) da ictiofauna acompanhante associada a pesca do camarão-da-amazônia, na cidade de Santarém (PA). Intervalos de confiança $(\alpha=0,05)$ em linhas verticais.
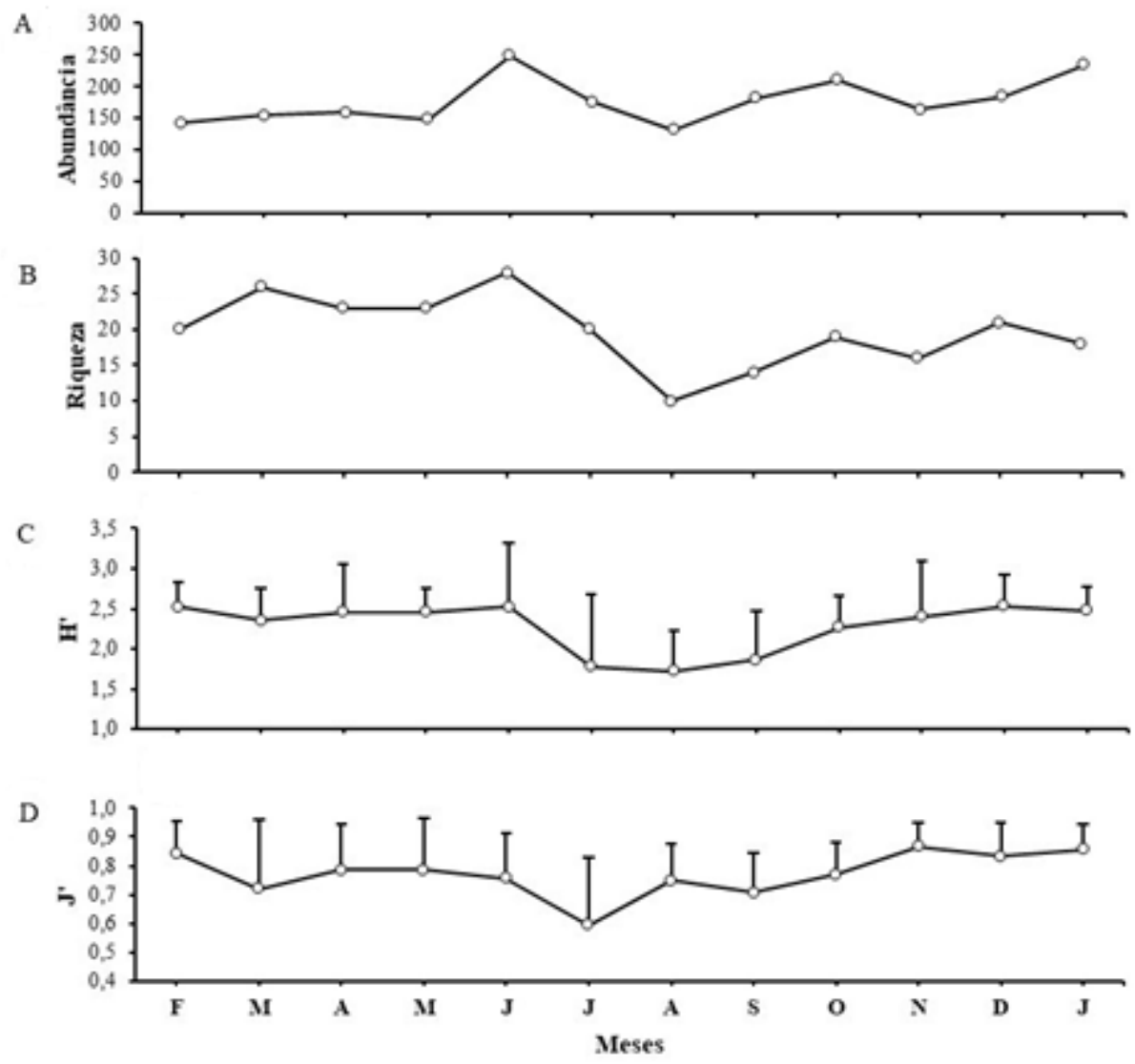

Neste estudo, a espécie Hypoptopoma elongatum foi a única que ocorreu em todos os meses, seguida de Colomesus asellus e Crenicichla reticulata que ocorreram em 9 meses, somente 7 espécies foram classificadas como muito frequentes, a maioria (29) foram consideradas como pouco frequentes e ocasionais (24), com ocorrência registrada de 1 a 3 meses. Somente os meses de junho e agosto possuíram diferenças significativas na composição específica das espécies, ressaltando que até o mês de setembro foram inseridas pelo menos uma espécie diferente nas amostragens, em especial ao mês junho que das 28 espécies capturadas, 13 eram espécies novas, com destaque para M. insignis, Peckoltia sp. P. trimaculatus, A. microlepis, C. flavescens, a últimas espécies a aparecer nas coletas foram $P$. squamosissimus e P. cayana. 
Algumas espécies encontradas como P. flavipinnis, L. friderici, L. fasciatus, Hemiodus spp., G. megasema, $P$. squamosissimus, $P$. rutiloides e $P$ cristata são comercializadas em feiras livres e mercados da região, entretanto, elas são descartadas e devolvidas ao rio, por apresentarem tamanho insuficiente e por serem capturadas em baixa abundância, impossibilitando o aproveitamento tanto para o consumo como para a comercialização (tamanho inadequado), além de não possuírem potencial para uso alternativo.

Essa tendência também foi registrada por outros estudos, onde a maioria dos peixes capturados que estão em fase juvenil, são espécies de pequeno porte ou possuem apenas importância ecológica, sem aproveitamento comercial e, por isso o descarte desses indivíduos se torna algo comum o que dificulta e torna mais difícil a avaliação das variações ocorrentes nas populações naturais (Bail e Branco 2010; Bernardes Júnior et al. 2011; Sedrez et al. 2013).

De acordo com Coelho et al. (2020) a captura da fauna acompanhante é o principal motivo gerador da alta disputa por recursos e conflitos entre pescadores que também utilizam a mesma área de pesca em Santarém. Os quais afirmam que a causa da diminuição dos peixes é exatamente determinada pela captura indevida de juvenis, seguida do descarte (grande maioria já mortos), o que gera inúmeras tensões e problematizações na pesca, além de furto dos camarões e destruição das armadilhas.

Foi observado uma mudança temporal dos índices de diversidade de Shannon ( $\left.\mathrm{H}^{\prime}\right)$ e a equitabilidade de Pielou ( $\mathrm{J}$ '), os resultados encontrados foram superiores aos mencionados em outras regiões (Bail e Branco 2010; Cattani et al. 2011). Destaca-se, que os índices podem ter sido influenciados pela dominância de poucas espécies, pela falta de áreas de refúgio e alimentos para jovens (em determinados meses), presença de espécies predadoras e forrageiras, além de um possível aumento do esforço de pesca, como mencionado por Sedrez et al. (2013) na pesca artesanal do camarão sete-barbas (Xiphopenaeus kroyeri) no litoral sul do Brasil. Entretanto, como a média anual do índice de equitabilidade se manteve consistente e acima de 0,5 é possível afirmar que a distribuição sazonal foi relativamente uniforme entre as espécies ao longo dos meses do ano na área estudada.

O resultado do diagrama de Whittaker mostra a importância das espécies a partir das mais comuns e/ou mais abundantes até as mais raras, com destaque para a dominância de seis espécies que representaram mais da metade das capturas $(63,21 \%)$, em ordem decrescente de abundância, são elas: C. asellus, O. punctata, C. heckelii, P. blochii, H. elongatum e P. cristata. No total essas espécies somaram 1.080 exemplares capturados (Figura 5). Esse padrão de dominância de poucas espécies associadas a pesca de camarões também foi observado em outras regiões do Brasil (Bernardes Júnior et al. 2011; Stanski et al. 2016). 
Figura 5. Diagrama de Whittaker representando as espécies da ictiofauna acompanhante da mais a menos dominante, a linha horizontal separa as espécies dominantes das outras consideradas raras.

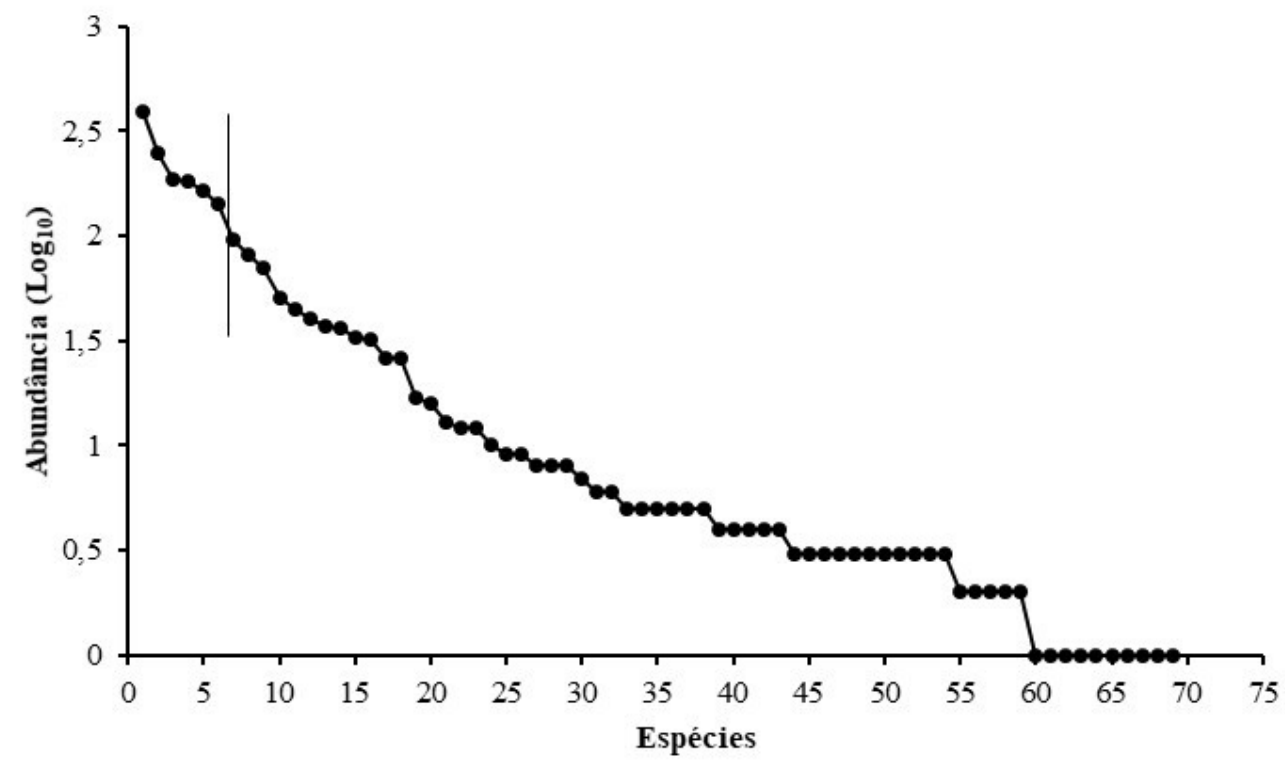

A análise de similaridade formou dois grupos diferentes (a - águas altas) e (b - águas baixas), onde esses agrupamentos foram subdivididos em outros três (1a - cheia, $2 \mathrm{a}$ - enchente e $1 \mathrm{~b}$ - vazante e seca), exibindo um padrão sazonal com associação e relação intrínseca das espécies da ictiofauna acompanhante com as fases do ciclo hidrológico local (Figura 6).

Figura 6. Agrupamento realizado com base no coeficiente de similaridade de Bray-Curtis levando em consideração a presença/ausência da ictiofauna acompanhante capturada por armadilhas de camarões ao longo dos meses de amostragem em Santarém (PA).

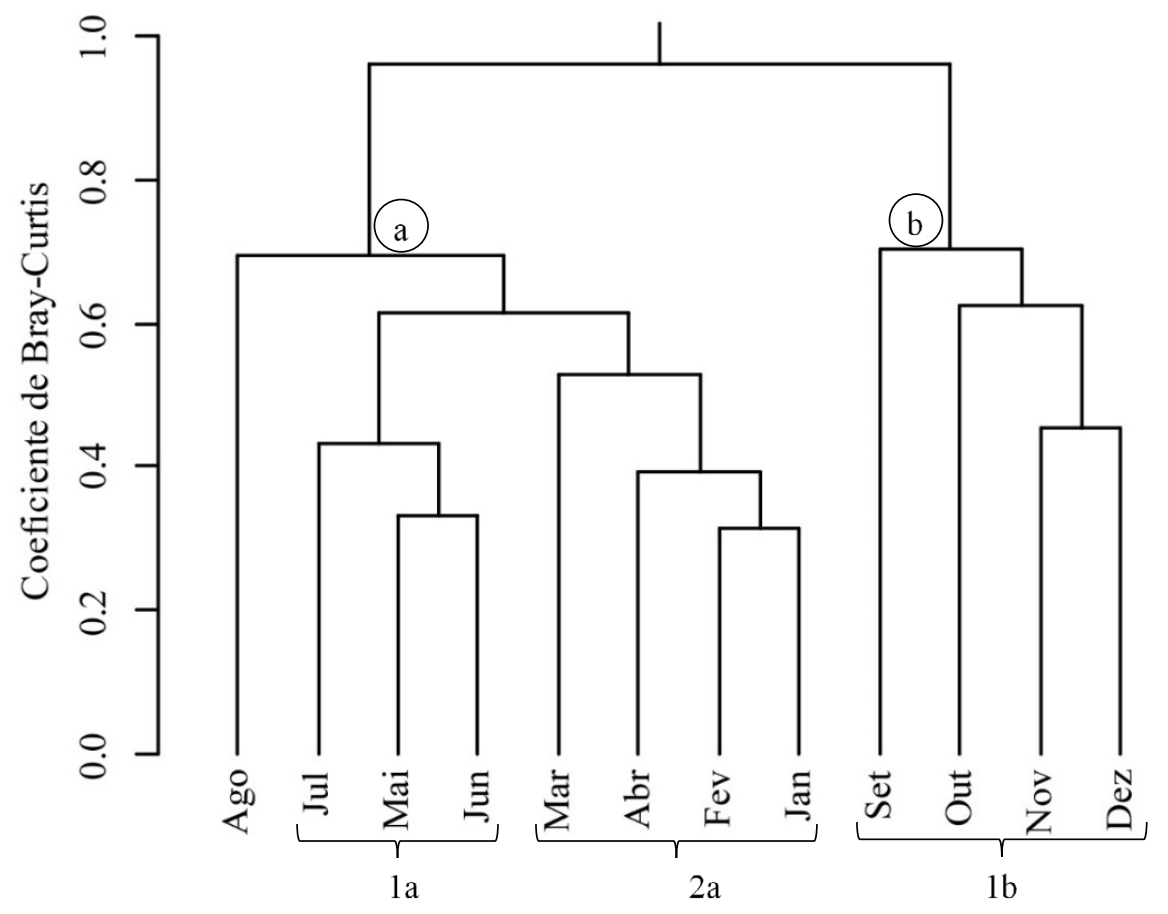


Esses resultados são corroborados por diversos autores que relatam que a abundância e riqueza da comunidade íctica nos rios amazônicos é afetada pelo ciclo hidrológico, sendo a principal força que rege o comportamento e distribuição espaço-temporal da ictiofauna. Essa diferença nos níveis, cota e vazão de água entre o período chuvoso e seco, impõe uma forte sazonalidade, envolvendo o pulso de inundação e as migrações da ictiofauna que adentram e em seguida abandonam as áreas alagadas para a reprodução. Essa dinâmica influencia diretamente na composição específica, volume e biomassa de pescado capturado e desembarcado na região de Santarém (Bentes et al. 2018; Serrão et al. 2019; Ponte et al. 2019; Zacardi, 2020), um fenômeno também reportado para outras áreas da bacia Amazônica (Freitas et al. 2010; Lima et al. 2015; Röpke et al. 2016).

\section{Conclusão}

A pesca do camarão-da-amazônia na região de Santarém é feita com armadilhas semifixas direcionadas para a captura da espécie-alvo, entretanto, a variação da amplitude de comprimento das espécies de peixes demonstra que as armadilhas semifixas utilizadas para capturar camarões está aprisionando de pequeno porte e/ou indivíduos juvenis, que são descartados pelos pescadores por não apresentarem tamanho suficiente, pouco ou nenhum valor comercial. Essa prática, do ponto de vista conservacionista, pode ser preocupante por interferir no ciclo natural desses indivíduos, com consequências previsíveis para o recrutamento de suas populações, ameaçando a manutenção dos estoques naturais.

A proporção de ictiofauna acompanhante e camarão assinala uma produção constituída majoritariamente pela espécie-alvo (camarão), mostrando a eficiência na captura e que a pesca com armadilhas (matapis) é uma técnica passiva podendo ser considerada praticamente "monoespecífica" e "seletiva" quando comparadas a outros métodos de captura de camarões de baixa seletividade, como as redes de arrasto.

$\mathrm{O}$ atual estudo não permite um diagnóstico completo da pescaria de camarões e nem um detalhamento sobre a diversidade total e/ou mudanças sazonais ocorridas na composição da ictiofauna acompanhante. Mas, essas informações são importantes tanto em termos ecológicos quanto econômicos, podendo subsidiar adoção de políticas públicas necessárias e contribuir para a melhoria dessas pescarias com armadilhas semifixas direcionada aos camarões-da-amazônia praticadas no Baixo Amazonas, colaborando para futuras ações sustentáveis na região.

Pode-se concluir que é necessário maior periodicidade, duração e estudos contínuos para conhecer melhor essa prática de pesca em Santarém (PA) a fim de se garantir o desenvolvimento de estratégias de manejo dos recursos pesqueiros e a conservação da biodiversidade. Para isso, os gestores de pesca precisam monitorar a atividade, instruir medidas que reduzam a captura incidental de peixes, pensando em dispositivos na rede ou no uso de nova estratégia de pesca e que possam permitir o escape de indivíduos menores (que não seriam comercializados ou consumidos), possíveis locais de exclusão de pesca, introduzir abordagens participativas estimulando iniciativas colaborativas para melhorar a condução e o engajamento dos pescadores para uma pesca artesanal responsável, entre outros. Essas ferramentas de ordenamento pesqueiro podem ajudar a alcançar a sustentabilidade, beneficiando a população de pescadores artesanais, bem como garantir alimento, renda, trabalho e desenvolvimento socioeconômico da região. 
Ictiofauna acompanhante associada a pesca do camarão-da-amazônia Macrobrachium amazonicum (Heller, 1862) (Decapoda, Palaeomonidae): subsídios para gestão ambiental e ordenamento da pesca

Participação dos autores: LCI, YKSC - coleta de campo, triagem de material, análise dos dados, redação do manuscrito; EMS, DMZ - coleta de campo, redação do manuscrito, coordenação do projeto.

Aprovação ética e outras licenças: trabalho aprovado pelo Comitê de Ética em Pesquisa (CEP), da Universidade Federal do Oeste do Pará, sendo aprovada pelo parecer n 1.999.965, em 04/04/2017; Aprovação SISBIO/ ICMBio n. 72330.

Disponibilidade dos dados: os dados da pesquisa estão disponíveis mediante solicitação no site do Laboratório onde a pesquisa esteve vinculada -https://leipaiufopa.com/dados-ictiofauna-acompanhante/.

Fomento: não houve qualquer fonte de fomento.

Conflito de Interesses: não há conflitos de interesse.

\section{Referências}

Ansari ZA, Chatterfi A, Ingole BS, Sreepada RA, Rivonkar CU, Parulekar AH. 1995. Community structure and seazonal variation of on inshore demersal fish community at Goa, west coast of India. Estuarine Coastal and Shelf Science, 41(5):593-610. https://doi.org/10.1016/0272-7714(95)90029-2.

Bail GC, Branco JO. 2010. Ocorrência, abundância e diversidade da ictiofauna na pesca do camarão sete-barbas, na região de Penha, SC. Brazilian Journal of Aquatic Science and Technology, 7(1):73-82. http://dx.doi.org/10.14210/ bjast.v7n1.p73-82.

Bentes KLS, Oliveira LL, Zacardi DM, Barreto NJC. 2018. The relationship between hydrologic variation and fishery resources at the lower Amazon, Santarém, Pará. Revista Brasileira de Geografia Física, 11(4):1478-1489. https://doi. org/10.26848/rbgf.v11.4.p1478-1489.

Bernardes Júnior JJ, Rodrigues Filho JL, Branco JO, Verani JR. 2011. Spatio-temporal variations of the ichthyofaunal structure accompanying the seabob shrimp, Xiphopenaeus kroyeri (Crustacea: Penaeidae), fishery in important fishery areas of the Santa Catarina shore, Brazil. Zoologia (Curitiba), 28(2):151-164. http://dx.doi.org/10.1590/S198446702011000200002 .

Branco JO, Lunardon-Branco MJ, Verani JR. 2005. Aspectos biológicos e pesqueiros de Paralonchurus brasiliensis Steindachner, (Pisces, Sciaenidae), na Armação do Itapocoroy, Penha, Santa Catarina, Brasil. Revista Brasileira de Zoologia, 22(4):1063-1071. http://dx.doi.org/10.1590/S0101-81752005000400035.

Brejão GL, Gerhard P, Zuanon J. 2013. Functional trophic composition of the ichthyofauna of forest streams in eastern Brazilian Amazon. Neotropical Ichthyology, 11(2):361-373. http://dx.doi.org/10.1590/S1679-62252013005000006.

Carvalho AR, Pennino MG, Bellido JM, Olavo G. 2019. Small-scale shrimp fisheries bycatch:A multi-criteria approach for data-scarse situations. Marine Policy, 103613. https://doi.org/10.1016/j.marpol.2019.103613.

Cattani AP, Santos LO, Spach HL, Budel BR, Guanais JHDG. 2011. Assessment of ichthyofauna bycatch of the seabob shrimp fishery from the municipality of Pontal do Paraná, Paraná coast, Brazil. Boletim do Instituto de Pesca, $37(2): 247-260$.

Coelho YKS, Imbiriba LC, Serrão EM, Zacardi DM. 2020. A pesca camaroeira em Santarém, Baixo Amazonas, Pará: procedimentos técnicos e operacionais. Gaia Scientia, 14(1):166-178. https://doi.org/10.22478/ufpb.1981$1268.2020 \mathrm{v} 14 \mathrm{n} 1.50238$

Corrêa JM, Gerhard P, Figueiredo RDO. 2012. Ictiofauna de igarapés de pequenas bacias de drenagem em área agrícola do Nordeste Paraense, Amazônia Oriental. Revista Ambiente \& Água, 7(2):214-230. https://doi.org/10.4136/ambiagua.739.

Costa DAS, Martins JC, Silva KCA, Klautau AGCM, Cintra IHA. 2016. Seletividade do matapi nas capturas de Macrobrachium amazonicum no baixo rio Tocantins, Amazônia, Brasil. Boletim do Instituto da Pesca, 42(2):403-417. https://doi.org/10.20950/1678-2305.2016v42n2p403. 
Costa TV, Mattos LA, Machado NJB. 2016. Estrutura populacional de Macrobrachium amazonicum em dois lagos de várzea da Amazônia. Boletim do Instituto da Pesca, 42(2):281-293. https://doi.org/10.20950/1678-2305.2016v42n2p281.

Davies RWD, Cripps SJ, Nickson A, Porter G. 2009. Defining and estimating global marine fisheries bycatch. Marine Policy, 33(4):661-672. https://doi.org/10.1016/j.marpol.2009.01.003.

Falcão MG, Pichler HA, Félix FC, Spach HL, Barril ME, Araújo KCB, Godefroid RS. 2008. A ictiofauna como indicador de qualidade ambiental em planícies de maré do complexo estuarino de Paranaguá, Brasil. Cadernos da Escola de Saúde Ciências Biológicas, 1:1-16.

Farias EG, Pereira-Júnior AC, Domingos MM, Dantas DV. 2019. Proposed bycatch-reduction modifications of shrimp fyke nets used in South American lagoons. Acta Ichthyologica et Piscatoria, 49(1):1-7. https://doi.org/10.3750/ AIEP/02357.

Ferreira EJG, Zuanon J, Forsberg B, Goulding M. Briglia-Ferreira R. 2007. Rio Branco: peixes, ecologia e conservação de Roraima. Amazon Conservation Association (ACA)/Instituto Nacional de Pesquisas da Amazônia (INPA)/Sociedade Civil Mamirauá, 201 p.

Ferreira EJG, Zuanon JAS, Santos GM. 1998. Peixes Comerciais do Médio Amazonas: região de Santarém, Pará. Edições IBAMA. Brasília, DF. 214 p.

Fonseca AF, Souza RAL. 2013. Caracterização ecológica de algumas espécies da fauna acompanhante do camarão capturado com puçá de arrasto na zona estuarina do rio Taperaçu (Bragança-PA-Brasil). Boletim Técnico Científico do CEPNOR, 6(1):33-47. http://dx.doi.org/10.32519/tjfas.v6i1.1240.

Franco AA, Bilce JM, Silva SAA, Santos RC, Oliveira VAM. 2015. Ictiofauna do córrego curió da primavera, sub-bacia do rio Teles Pires, Alto Tapajós. Enciclopédia Biosfera, 11(22):1428-1440. http://dx.doi.org/10.18677/Enciclopedia_ Biosfera_2015_172.

Freitas CEDC, Siqueira-Souza FK, Guimarães AR, Santos FA, Santos IL. 2010. Interconnectedness during high water maintains similarity in fish assemblages of island floodplain lakes in the Amazonian Basin. Zoologia, 27(6):931-938. http://dx.doi.org/10.1590/S1984-46702010000600014.

Freitas MO, Spach HL, Hostim-Silva M. 2011. Variação espaço-temporal da assembleia de peixes demersais em uma área de pesca do camarão sete-barbas no sul do Brasil. Neotropical Biology and Conservation, 6(1):44-54. http://dx.doi. org/10.4013/nbc.2011.61.06.

Galvis G, Mojica JI, Duque SR, Castellanos C, Sánchez-Duarte P, Arce M, Gutiérrez A, Jiménez LF, Santos M, Vejarano S, Arbeláez F, Prieto E, Leiva M. 2006. Peces del medio Amazonas. Región de Leticia. Conservación Internacional, serie de guías tropicales de campo, Bogotá, 546 p.

Hercos AP, Queiroz Hl, Lazzarotto HA 2009. Peixes Ornamentais do Amanã. 1. ed. Tefé: MCT/IDSM, 241 p.

Lima JF, Montagner D. 2014. Aspectos gerais da pesca e comercialização do camarão-da Amazônia no Amapá. Embrapa Amapá, 18 p.

Lima MAL, Hauser M, Doria CRC. 2015. Principais espécies de peixes capturadas pela pesca comercial entre Costa Marques e Humaitá. In: Doria CRC, Lima MAL (Orgs.). Rio Madeira: seus peixes e sua pesca. Porto Velho: EDUFRO, 2015. p. 129-153.

Loebens SC, Yamamoto KC. 2016. Diversidade de assembleias de peixes em floresta alagada de águas pretas da Amazônia Central. Scientia Amazonia, 5(1):37-44.

Maciel CR, Valenti WC. 2009. Biology, fisheries, and aquaculture of the Amazon River Prawn Macrobrachium amazonicum: a review. Nauplius, 17(2):61-79.

Magurran AE. 2004. Measuring biological diversity. Oxford, Blackwell Science, 256 p. 
Ictiofauna acompanhante associada a pesca do camarão-da-amazônia Macrobrachium amazonicum (Heller, 1862) (Decapoda, Palaeomonidae): subsídios para gestão ambiental e ordenamento da pesca

Maia BP, Nunes ZMP, Holanda FCAF, Silva-Silva VH, Silva BB. 2016. Gradiente latitudinal da beta diversidade da fauna acompanhante das pescarias industriais de camarões marinhos da costa Norte do Brasil. Biota Amazônia, 6(1):31-39 http://dx.doi.org/10.18561/2179-5746/biotaamazonia.v6n1p31-39.

Mérona B, Juras AA, Santos GM, Cintra IHA. 2010. Os peixes e a pesca no baixo rio Tocantins: vinte anos depois da UHE Tucuruí. Belém: Eletrobras/ Eletronorte, 208p.

Montag LFA, Winemiller KO, Keppeler FW, Leão H, Benone NL, Torres NR, Prudente BS, Begot TO, Bower LM, Saenz DE, Lopez-Delgado EO, Quintana Y, Hoeinghaus DJ, Juen L. 2018. Land cover, riparian zones and instream habitat influence stream fish assemblages in the eastern Amazon. Ecology of Freshwater Fish, 28(2):317-329. https://doi. org/10.1111/eff.12455.

Ohara WM, Lima FCT, Salvador GN, Andrade MC. 2017. Peixes do rio Teles Pires: diversidade e guia de identificação. Gráfica Amazonas e Editora Ltda-EPP, Aparecida de Goiânia. 399 p.

Oksanen J, Blanchet F, Kindt R. 2016. Vegan: Community ecology package. R Package Version.

Pinheiro HT, Martins AS. 2018. Estudo comparativo da captura artesanal do camarão sete-barbas e sua fauna acompanhante em duas áreas de pesca do litoral do estado do Espírito Santo, Brasil. Boletim do Instituto de Pesca, 35(2):215-225.

Ponte SCS, Oliveira LS, Zacardi DM. 2019. Variação temporal de larvas de peixes de um lago de inundação como subsídio à gestão ambiental. Journal of Applied Hydro-Environment and Climate, 1(1):1-13.

Queiroz LJ, Torrente-Vilara G, Ohara WM, Pires THS, Zuanon J, Doria CRC. 2013. Peixes do rio Madeira. Vol. (1-3). São Paulo: Dialeto. 399 p.

R Core Team. 2018. R: A Language and Environment for Statistical Computing. R Foundation for Statistical Computing, Vienna. Disponível em: https://www.rproject.org/.

Röpke CP, Amadio AS, Winemiller KO, Zuanon J. 2016. Seasonal dynamics of the fish assemblage in a floodplain lake at the confluence of the Negro and Amazon Rivers. Journal of Fish Biology, 89(1):194-212.

Santos MCF, Almeida, L, Silva CGM. 2008. Avaliação quali-quantitativa da ictiofauna acompanhante na pesca do camarão sete-barbas, Xiphopenaeus kroyeri (Heller, 1862) no município de Caravelas (Bahia-Brasil). Boletim TécnicoCientífico do CEPENE, 16(1):99-107.

Sedrez MC, Branco JO, Freitas Junior F, Monteiro HS, Barbieri E. 2013. Ictiofauna acompanhante na pesca artesanal do camarão sete-barbas (Xiphopenaeus kroyeri) no litoral sul do Brasil. Biota Neotropical, 13(1):164-175. https://doi. org/10.1590/S1676-06032013000100019.

Serrão EM, Braga TMP, Coêlho YKS, Campos DPF, Imbiriba LC, Suzuki MAL, Ponte SCS, Zacardi DM. 2019. Caracterização da pesca e percepção ambiental de pescadores de um lago de inundação no Baixo Amazonas: Perspectivas para o manejo. Pp. 49-87. In: Lima, ACB, Almeida OT. (Orgs.). Uso de recursos naturais na Amazônia: experiências locais e ferramentas para governança. Belém:GAPTA/UFPA, $259 \mathrm{p}$.

Silva AIW, Faria-Junior CH. 2018. Consumo de pescado e outros alimentos pela população indígena da aldeia Mapuera, Oriximiná, Pará. Revista Ciências da Sociedade, 2(4):54-78. http://dx.doi.org/10.30810/rcs.v2i4.902.

Silva MAG, Guimarães JMJ, Silva NFC, Santos FCV, Ucker FE. 2016. Caracterização pluviométrica de Santarém-Pa, Brasil. Renefara, 10:112-120.

Sousa RGC, Florentino AC, Piñeyro JIG. 2014. Inovação de artefatos e caracterização da pesca do camarão Macrobrachium amazonicum (Heller, 1862) na comunidade São Sebastião da Brasília-Parintins/AM. Biota Amazônia, 4(3):83-87. http:// dx.doi.org/10.18561/2179-5746/biotaamazonia.v4n3p83-87. 
Souza TR, Carminatto AA, Barreto TMRR, Cardoso GS, Ramires M, Barrella W, Rotundo MM. 2019. Análise da ictiofauna acompanhante da pesca do camarão sete-barbas na Barra do Una - Peruíbe, São Paulo, Brasil. In: Anais do Encontro Nacional de Pós-Graduação - VIII ENPG, Universidade Santa Cecília, Santos, São Paulo, 3:287-291.

Sousa RP, Miranda KF, Freire JS. 2011. (Org.). Manejo comunitário de camarões e sua relação com a conservação da floresta no estuário do Rio Amazonas: sistematização de uma experiência em Gurupá-PA. Belém, PA: Instituto Internacional de Educação do Brasil, 76 p.

Stanski G, Mantelatto FL, Leão-Castilho AL. 2016. Hermit crab bycatch fauna (Decapoda, Anomura) off the coast of Santa Catarina State, Brazil: diversity and spatial-temporal distribution. Latin American Journal of Aquatic Research, 44(3):546-5566. http://dx.doi.org/10.3856/vol44-issue3-fulltext-13.

Tischer M, Santos MCF. 2001. Algumas considerações sobre a ictiofauna acompanhante da pesca de camarões na foz do rio São Francisco Alagoas/Sergipe - Brasil). Boletim Técnico Científico CEPENE, 9(1):155-165.

Vaz EM, Rabelo YGS, Correa JMS, Zacardi DM. 2017. A pesca artesanal no lago Maicá: aspectos socioeconômicos e estrutura operacional. Biota Amazônia, 7(4):6-12. http://dx.doi.org/10.18561/2179-5746/biotaamazonia.v7n4p6-12.

Vieira WJ, Domingos MM, Rodrigues-Filho JL, Farias EG. 2017. Kite escape device:A new approach to reduce bycatch in shrimp trawls. Marine and Coastal Fisheries, 9(1):396-403. https://doi.org/10.1080/19425120.2017.1347114.

Zacardi DM. 2020. A pesca artesanal em áreas de inundação no Baixo Amazonas, Pará: técnicas de captura e composição pesqueira. Pp. 25-34. In: Aquicultura e Pesca: Adversidades e Resultados 3. Ponta Grossa, PR: Atena Editora. 